\title{
Erratum to: Isolated hepatic perfusion as a treatment for uveal melanoma liver metastases (the SCANDIUM trial): study protocol for a randomized controlled trial
}

\author{
Roger Olofsson Bagge ${ }^{{ }^{*}}$, Lars Ny ${ }^{2}$, Charlotta All-Ericsson ${ }^{3}$, Malin Sternby Eilard ${ }^{4}$, Magnus Rizell $^{4}$, Christian Cahlin $^{4}$,
} Ulrika Stierner ${ }^{2}$, Ulf Lönn ${ }^{5}$, Johan Hansson ${ }^{6}$, Ingrid Ljuslinder ${ }^{7}$, Lotta Lundgren ${ }^{8}$, Gustav Ullenhag ${ }^{9}$,

Jens Folke Kiilgaard ${ }^{10}$, Jonas Nilsson ${ }^{11}$ and Per Lindnér ${ }^{4}$

\section{Erratum}

After publication of this work [1], we noted that we failed to include the complete list of all coauthors. The full list of authors has now been updated. The Authors' contributions and Competing interests section modified accordingly. We are publishing this erratum to update the author list, which is as follows:

Roger Olofsson, Lars Ny, Charlotta All-Ericsson, Malin Sternby Eilard, Magnus Rizell, Christian Cahlin, Ulrika Stierner, Ulf Lönn, Johan Hansson, Ingrid Ljuslinder, Lotta Lundgren, Gustav Ullenhag, Jens Folke Kiilgaard, Jonas Nilsson and Per Lindnér.

\section{Competing interests}

None of the authors has any competing interests.

\section{Authors' contributions}

$R O$ and $P L$ designed the study together with $L N, C A E, M S E, M R, C C, U S, U L$, $J H, I L, L L, G U, J F K$ and JN, who contributed in the design of the study during several meetings. $R O$ and PL drafted the manuscript together with $L N, M S E$, MR, CC, US, UL, JH, IL, LL, GU, JFK and JN. RO is co-ordinating investigator of the trial, $L N, U S, U L, J H, I L, L L, G U$ are local primary investigators. All authors read and approved the final manuscript.

\section{Author details}

${ }^{1}$ Department of Surgery, Institute of Clinical Sciences, Sahlgrenska Academy at University of Gothenburg, Sahlgrenska University Hospital, 41345 Gothenburg, Sweden. ²Department of Oncology, Institute of Clinical Sciences, Sahlgrenska Academy at University of Gothenburg, Sahlgrenska University Hospital, Gothenburg, Sweden. ${ }^{3}$ St. Erik Eye Hospital, Karolinska Institutet, Stockholm, Sweden. ${ }^{4}$ Transplant Institute, Institute of Clinical Sciences, Sahlgrenska Academy at University of Gothenburg, Sahlgrenska University Hospital, Gothenburg, Sweden. ${ }^{5}$ Department of Oncology, Linköping University Hospital, Linköping, Sweden. ${ }^{6}$ Department of Oncology, Karolinska University Hospital, Stockholm, Sweden. ${ }^{7}$ Department of Oncology,

\footnotetext{
* Correspondence: roger.olofsson@surgery.gu.se

${ }^{1}$ Department of Surgery, Institute of Clinical Sciences, Sahlgrenska Academy at University of Gothenburg, Sahlgrenska University Hospital, 41345 Gothenburg, Sweden

Full list of author information is available at the end of the article
}

Norrlands University Hospital, Umeå, Sweden. ${ }^{8}$ Department of Oncology, Skåne University Hospital, Lund, Sweden. ${ }^{9}$ Department of Radiology, Oncology and Radiation Science, Section of Oncology, Uppsala University, Uppsala, Sweden. ${ }^{10}$ Department of Ophthalmology, Glostrup Hospital, Copenhagen University Hospital Glostrup, Glostrup, Denmark. ${ }^{11}$ Sahlgrenska Cancer Center, Sahlgrenska Academy at University of Gothenburg, Sahlgrenska University Hospital, Gothenburg, Sweden.

Received: 27 April 2015 Accepted: 16 June 2015

Published online: 06 August 2015

\section{Reference}

1. Olofsson R, Ny L, Eilard MS, Rizell M, Cahlin C, Stierner U, et al. Isolated hepatic perfusion as a treatment for uveal melanoma liver metastases (the SCANDIUM trial): study protocol for a randomized controlled trial. Trials. 2014;15:317.

\section{Submit your next manuscript to BioMed Central and take full advantage of:}

- Convenient online submission

- Thorough peer review

- No space constraints or color figure charges

- Immediate publication on acceptance

- Inclusion in PubMed, CAS, Scopus and Google Scholar

- Research which is freely available for redistribution 